Abstracta Iranica Iranica

Revue bibliographique pour le domaine irano-aryen

Volume 30 | 2010

Comptes rendus des publications de 2007

\title{
Die Inkulturation des Christentums im Sasanidenreich. Wiesbaden, Reichert, 2007, 324 p.
}

\section{Christelle Jullien}

\section{(2) OpenEdition}

1 Journals

Édition électronique

URL : http://journals.openedition.org/abstractairanica/37887

DOI : 10.4000/abstractairanica.37887

ISSN : 1961-960X

\section{Éditeur :}

CNRS (UMR 7528 Mondes iraniens et indiens), Éditions de l'IFRI

\section{Édition imprimée}

Date de publication : 8 avril 2010

ISSN : 0240-8910

\section{Référence électronique}

Christelle Jullien, «Die Inkulturation des Christentums im Sasanidenreich. Wiesbaden, Reichert, 2007, 324 p. », Abstracta Iranica [En ligne], Volume 30 | 2010, document 207, mis en ligne le 08 avril 2010, consulté le 26 septembre 2020. URL : http://journals.openedition.org/abstractairanica/37887 ; DOI : https://doi.org/10.4000/abstractairanica.37887

Ce document a été généré automatiquement le 26 septembre 2020.

Tous droits réservés 


\title{
Die Inkulturation des Christentums im Sasanidenreich. Wiesbaden, Reichert, 2007, 324 p.
}

\author{
Christelle Jullien
}

1 Il s'agit d'un ouvrage collectif composé d'articles sur le thème de l'inculturation du christianisme dans l'empire sassanide (224-651). Neuf axes ont été privilégiés :

2 - l'époque apostolique avec un article de W. Hage (Marburg) sur la perception des débuts de l'Église orientale chez Barhebraeus, suivi d'une réflexion de G. P. Luttikhuizen (Gröningen) sur le milieu baptiste elchasaïte de l'enfance de Mani.

3 - le développement du manichéisme: les interprétations bibliques (S. G. Richter, Münster) ; A. L. Khosroyev (St. Petersburg) s'interroge sur la définition du manichéisme comme un courant christianisant d'identité perse; C. Reck (Berlin, BTT Institut) a travaillé sur les problèmes d'interprétation d'un texte fragmentaire qui laisserait penser qu'une protagoniste donnée pour chrétienne, Christina, aurait adopté des éléments de la foi manichéenne.

4 - l'adoption du pehlevi dans l'Église de Perse: A. Panaino s'intéresse au problème linguistique que pose l'attestation en version pâzand (pehlevi en écriture avestique) du Notre-Père, en s'attachant principalement à la source syriaque sous-jacente à la rédaction moyen-perse. Selon cet auteur, cette version tirerait davantage son origine de la Vetus Syra et du Diatessaron que de la Peshitta.

5 - les données archéologiques : S. R. Hauser (Berlin) établit un inventaire des évidences archéologiques de la présence chrétienne dans l'empire sassanide. J. Kröger (Berlin) a étudié plus spécifiquement l'église de Qasr bint al-Qadi et les autres sites ecclésiaux de Ctésiphon, la capitale.

6 - les relations Église et pouvoir dans l'empire sont relatées par J. Wiesehöfer (Kiel) et K. Mosig-Walburg (Frankfurt), qui s'attache plus spécialement à un panorama bien connu des persécutions de Shapur II (sur fond de guerre romano-perse). 
7 - le profil théologique de l'Église d'Orient. Les trois principaux courants christologiques sont présentés : syro-orthodoxe (Th. Hainthaler, Frankfurt) à partir de la lettre de Simeon de Beth-Arsham contre le nestorianisme en Perse; syro-oriental avec une réflexion sur la christologie de Mar Babaï par G. Chediath (Kottayam) ; enfin henanien (pro-chalcédonien) avec une présentation de la terminologie christologique employée dans l'œuvre du patriarche IshoCEyahb II de Gdala (628-646) par D. W. Winkler (Graz).

8 - L'image et la représentation du chrétien comme modèle de vie: l'exemplarité de la figure du patriarche de Séleucie-Ctésiphon par exemple (H. Suermann, Bonn), avec Sabrisho® $\mathrm{I}^{\text {er }}$, représentant de l'intégration réussie des chrétiens dans le milieu culturel iranien (M. Tamcke, Göttingen), ou Narsai chez Barhadbeshabba đEArbaya (K. Pinggéra, Marburg).

9 - l'inculturation du christianisme dans la liturgie (B. Schmitz, Hannovre), et, plus généralement syro-orientale (B. Varghese, Kottayam et J. Thekeparampil, Kottayam).

10 - Une ouverture est proposée par S. N. C. Lieu (Sydney), qui propose un survol historique de la question des missions nestoriennes vers la Chine.

\section{INDEX}

Thèmes : 6.3. Autres religions

\section{AUTEURS}

CHRISTELLE JULLIEN

CNRS/Mondes iranien et indien - Paris 